\title{
Preliminary Power Transient Analysis of the Super FR with Axially Heterogeneous Core
}

\author{
Tsutomu Okui ${ }^{1}$, Akifumi Yamaji ${ }^{1}$ \\ ${ }^{1}$ Waseda University \\ 3-4-1, Okubo, Shinjuku-ku, Tokyo, Japan \\ tsutomu0922@akane.waseda.jp
}

\begin{abstract}
The Super FR is one of the SuperCritical Water cooled Reactor (SCWR) concepts with oncethrough direct cycle plant system. Recently, new design concept of axially heterogeneous core has been proposed, which consists of multiple layers of MOX and blanket fuels. To clarify the safety performance during power transient, safety analyses have been conducted for uncontrolled control rod (CR) withdrawal and CR ejection at full power. RELAP/SCDAPSIM code was used for the safety analysis. The results show that the peak cladding surface temperature (PCST) is high in the upper MOX fuel layer. It is also shown that axial temperature gradient of cladding greatly increases in a short period. Suppressing such large temperature gradient may be a design issue for the axially heterogeneous core from the viewpoint of ensuring fuel integrity.
\end{abstract}

KEYWORDS: Axially heterogeneous core, Super FR, Power transient, RELAP/SCDAPSIM

\section{INTRODUCTION}

The Super FR is one of the SuperCritical Water cooled Reactor (SCWR) concepts with once-through direct cycle plant system [1][2]. The core is cooled with single-phase supercritical light water at 25.0 $\mathrm{MPa}$, which flows through the core without any phase changes and directly fed to the turbine. For the representative design of Super FR, the coolant enters the core at $280 \mathrm{C}$ at the bottom and flows up the coolant channels as it undergoes large temperature increase to the average outlet temperature of about 500 $\mathrm{C}$ [3]. Hence, keeping the fuel cladding temperature below certain limits is one of the key safety criteria of Super FR for abnormal transients and accidents.

The Super FR core is typically heterogeneously composed with seed fuel assemblies with Mixed OXide (MOX) fuel and blanket fuel assemblies with depleted uranium to attain high plutonium $(\mathrm{Pu})$ conversion (or breeding) performance and negative reactivity feedback through coolant density change [1][3]. Unlike some other SCWR design concepts, there are no reverse flows or preheating stages in the core and the entire coolant flows up the coolant channel in a single pass flow scheme [4]. The fuel assemblies are equipped with channel boxes and the coolant flow rate distribution to the fuel assemblies is determined with inlet orifices with consideration of reactivity buildup of blanket assemblies with burnup, so that the Maximum Cladding Surface Temperature (MCST) design criterion of $650 \mathrm{C}$ is satisfied throughout the normal operation cycle [3]. For such design concept, abnormal transient and accident analyses have been carried out, which have indicated that loss of coolant flow and loss of coolant events tend to be more limiting scenarios compared with reactivity insertion or overpower events [5]. 
More recently, Super FR with axially heterogeneous core configuration has been proposed and studied [6][7]. The core consists of alternative layers of MOX and blanket in the axial direction, which is similar to the past Boiling Water Reactor design concept [8]. Part of the core is also axially heterogeneous in a similar manner in the Chinese SCWR-M concept [9]. The axially heterogeneous Super FR core design study focused on suppressing radial core power swing with burnup so that more uniform core cooling can be achieved throughout the normal operation cycle. For such design, the core coolability may become an issue during power transients, because of the large axial power peaking in the MOX layer, especially near the top of the core, where the coolant temperature is high. However, such investigations have never been conducted.

Hence, the objective of this study is to evaluate the core coolability (i.e., cladding surface temperature) and reactivity feedback characteristics of Super FR with axially heterogeneous core during power transients. The five layers core (consisting of the lower blanket, lower MOX, inner blanket, upper MOX, upper blanket) is tentatively considered as the reference core design [10].

In the Super FR core, the coolant density is greatly reduced from about $750 \mathrm{~kg} / \mathrm{m}^{3}$ at the core inlet to less than $100 \mathrm{~kg} / \mathrm{m}^{3}$ near the core outlet as the coolant temperature is greatly increased [10]. Therefore, it is important to evaluate the transient behavior of the coolant mass flux, temperature, heat transfer rate, and reactivity feedback [11]. In this study, RELAP/SCDAPSIM is utilized with additional thermal-hydraulic models for supercritical water [12]. The Dittus-Boelter's correlation, which is widely used for evaluation of the single-phase heat transfer, is applied to the heat transfer calculations under supercritical pressure.

\section{PLANT DESIGN AND CORE CHARACTERISTICS}

\subsection{Plant control and safety system}

The basic plant control and safety system of Super FR is the same as that of the preceding studies as illustrated in Fig. 1 [13]. The core power is controlled by Control Rods (CRs), the pressure is controlled by turbine control valve or turbine bypass valve and the temperature of main steam line is controlled by feedwater pump [1]. Among the safety system, the relevant actuations for abnormal power transient events are:

- Reactor power high: reactor scram set point at $120 \%$ of the rated power

- Reactor period short: $10 \mathrm{~s}$

- Pressure high: reactor scram at 26.0 MPa; automatic depressurization system (ADS) actuation at 23.5 MPa; Safety Relief Valve (SRV) is assumed to open when the system pressure exceeds 26.2 MPa.

After the reactor scram and depressurization, the core injection systems are assumed to be actuated. The Auxiliary Feedwater System (AFS) is activated with $4 \%$ of the rated core flow rate at $25 \mathrm{MPa}$ and the Low Pressure Core Injection (LPCI) is activated when the core pressure is below $23.5 \mathrm{MPa}$ at $25 \%$ of the rated core flow rate. 


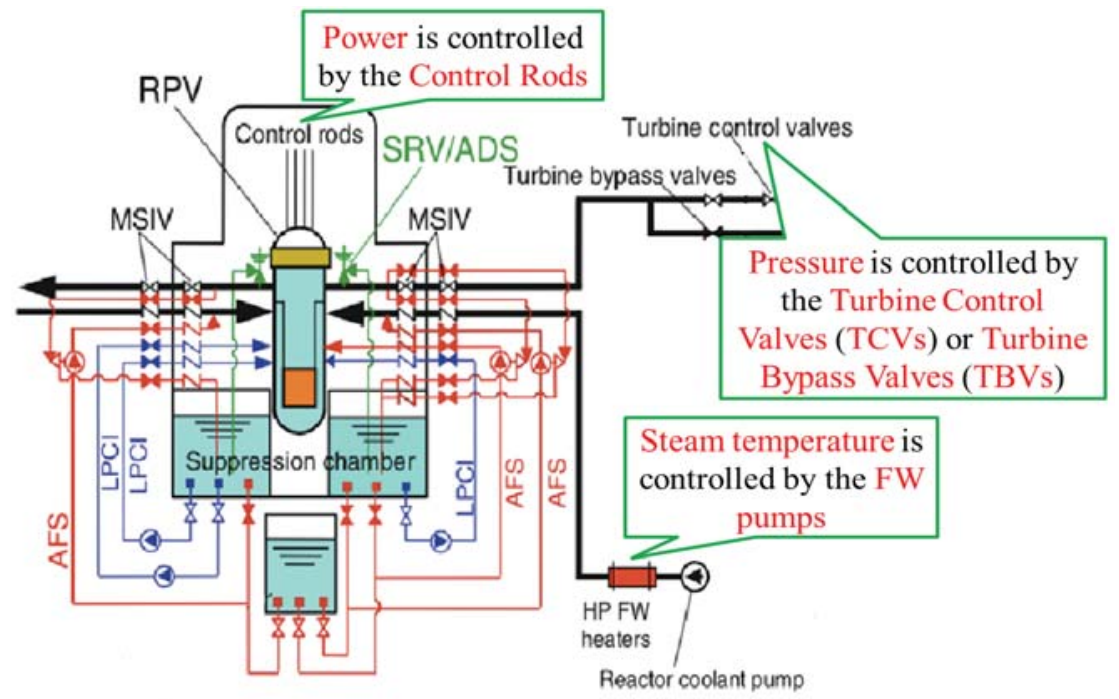

Figure 1: Plant control and safety system of Super FR [13]

\subsection{Core design specifications and characteristics}

The reference Super FR core generates thermal power of 2,867 MWth with estimated thermal efficiency of $42.2 \%$ and electric output of 1,210 MWe [10]. The core consists of 349 hexagonal fuel assemblies with tight lattice arrangement of fuel rods as shown in Fig. 2 (a). The fuel rod diameter and pitch are 9.05 $\mathrm{mm}$ and $9.55 \mathrm{~mm}$, respectively and the corresponding equivalent hydraulic diameter of the coolant channel is $2.1 \mathrm{~mm}$. The axial core configuration is shown in Fig. 2 (b). The MOX layer is fueled with 26$27 \mathrm{wt} \%$ enriched $\mathrm{Pu}$ and the core active height is $1400 \mathrm{~mm}$. The core inlet temperature is $295 \mathrm{C}$ and the average outlet temperature is $433 \mathrm{C}$ with MCST design limit of $650 \mathrm{C}$ for advanced stainless-steel cladding under normal operation condition.

The core design specifications and characteristics are summarized in Table I. The reactivity feedback coefficients shown in Table I are taken as the reference values, but they are also subject to sensitivity analyses.

Table I: The reference core design specifications and characteristics [10]

\begin{tabular}{|c|c|}
\hline Parameters & Design values \\
\hline Thermal power [MWth] & 2,867 \\
\hline ALHGR / MLHGR $[\mathrm{kW} / \mathrm{m}]$ & $9.3 / 38.1$ \\
\hline Axial power peaking at BOEC / EOEC & $2.52 / 2.65$ \\
\hline Inlet / Ave. outlet temperature / MCST [C] & 295 / 433 / 650 \\
\hline Inlet / Ave. outlet coolant density $\left[\mathrm{kg} / \mathrm{m}^{3}\right]$ & $752.3 / 120.3$ \\
\hline Coolant flow rate $[\mathrm{kg} / \mathrm{s}]$ & 1906 \\
\hline Fuel rod diameter / pitch / active height [mm] & $9.05 / 9.55 / 1400$ \\
\hline Pu enrichment [wt\%] (lower / upper) & $27 / 26$ \\
\hline Void reactivity coefficient at BOEC / EOEC $\left[10^{-4} \mathrm{dk} / \mathrm{k} / \%\right.$ void $]$ & $-0.08 /-1.00$ \\
\hline$\left.{ }^{*}\right)$ Density reactivity coefficient at BOEC / EOEC $[\% \mathrm{dk} / \mathrm{k} /(\mathrm{g} / \mathrm{cc})]$ & $2.73 / 6.20$ \\
\hline$\left(^{*}\right)$ Doppler reactivity coefficient at BOEC and EOEC $\left[10^{-4} \mathrm{dk} / \mathrm{k} / \mathrm{C}\right]$ & $-0.11 /-0.11$ \\
\hline Burnup $[\mathrm{GWd} / \mathrm{t}]$ (inner three layers / core average) & $65 / 52$ \\
\hline
\end{tabular}

$(*)$ Not found in the reference, but newly evaluated for the same core design. 


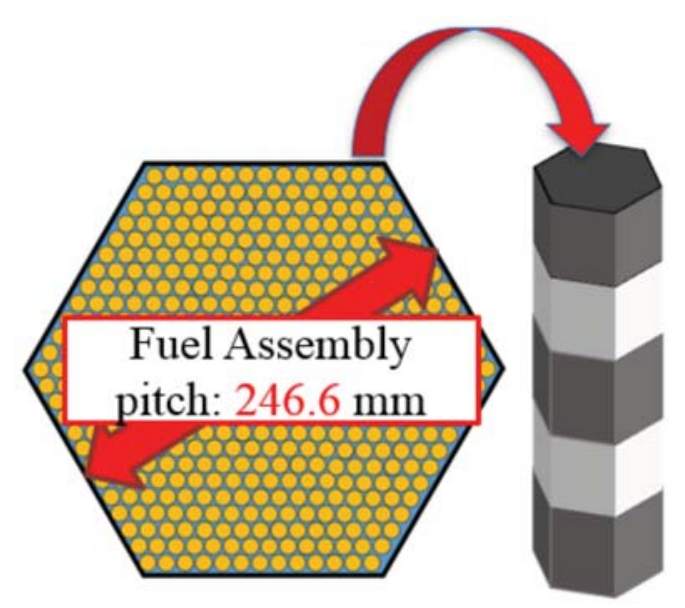

(a) Fuel assembly design

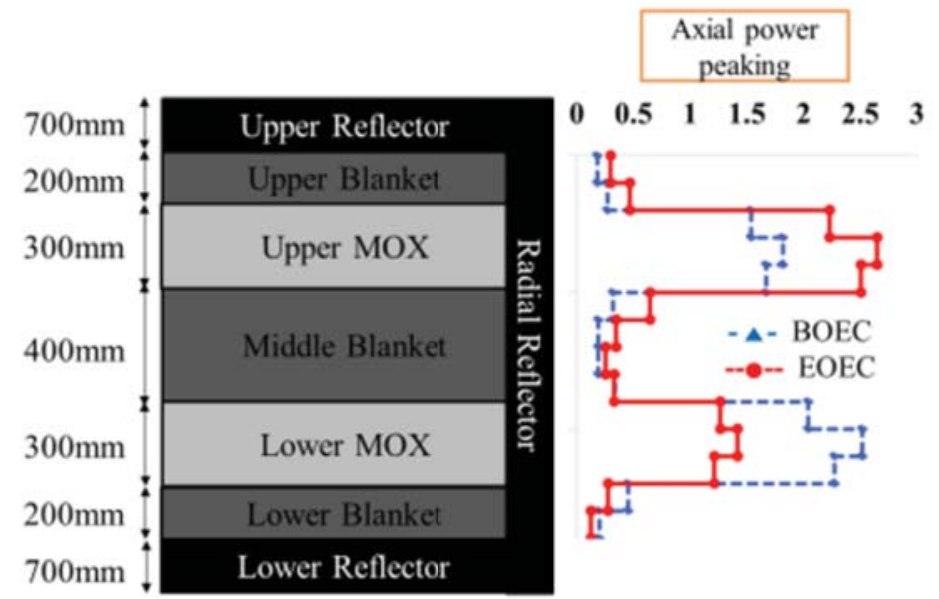

(b) Axial core configuration and power profiles

Figure 2: Fuel assembly design and axial core configuration [10]

\section{ANALYSIS METHOD AND SCENARIOS}

To evaluate power transient response of the system with consideration of reactivity feedback under supercritical pressure of water, RELAP/SCDAPSIM, developed at the Innovative Systems Software (ISS), has been utilized and adopted to the Super FR system. The code couples point reactor kinetics model with the reactor thermal hydraulics system with one-dimensional node junction model [12].

\subsection{Point kinetics model}

In this study, the core power distribution is assumed to be unchanged during the transient. The core power is calculated with the point kinetics model and decay heat model with six groups of delayed neutrons. In reality, for CR withdrawal or ejection scenarios, the core power near the CR is expected to increase locally and may influence the core coolability or fuel integrity [14]. Such evaluation requires threedimensional analysis and is beyond the scope of the current study, although it would have to be addressed in the future study for more in-depth investigation.

Generally, validity of the point kinetics model deteriorates when the reactivity change is localized such as the case for CR ejection. In this study, the same conservative approach is taken as the preceding study with assumption of the maximum reactivity worth of a CR to be $1.1 \$$, which is considered to be large enough to account for uncertainties associated with the point kinetics approximation [11].

In this study, the coolant density reactivity coefficient, which corresponds to the void reactivity coefficient of the reference design [10], is newly evaluated as shown in Table I and it is used in RELAP/SCDAPSIM.

\subsection{Heat transfer model}

There is large uncertainty associated with heat transfer with supercritical water cooling and various heat transfer correlations have been developed with most studies focusing on the heat transfer near the pseudocritical point and during heat transfer deterioration with low flow rate [4]. However, it is known that at supercritical conditions that are well beyond the critical or pseudo-critical points, single-phase heat transfer characteristics prevail and conventional $\mathrm{Nu}=\mathrm{f}(\mathrm{Re}, \mathrm{Pr})$ relationships are considered to be applicable for calculating heat transfer [4]. 
During power transient and reactivity insertion events, it is expected that the Peak Cladding Surface Temperature (PCST) appears in the region, which is well beyond the critical or pseudo-critical points [1]. Hence, in this study, the Dittus-Boelter correlation is used, as it is widely used for a single-phase flow [4].

\subsection{One-dimensional node junction model}

The one-dimensional node junction model for the plant system as described in Fig. 1 has been developed for RELAP/SCDAPSIM calculations. In this study, the inlet boundaries are represented with the Reactor Coolant Pump (RCP), Auxiliary Feedwater System (AFS), and Low Pressure Core Injection (LPCI) system. Similarly, the outlet boundaries are represented with the Main Steam Isolation Valve (MSIV), Safety Relief Valve (SRV), Turbine Control Valve (TCV), and Turbine Bypass Valve (TBV). The core is represented with three channels (cold, average, hot) and coolant flow rates to the channels are distributed with the inlet orifice models.

\subsection{Safety criteria and power transient scenarios}

In this study, the same set of safety criteria for the abnormal transients and accidents are considered as the preceding study [5]. Namely, the PCST $<850 \mathrm{C}$ and the peak pressure $<28.9 \mathrm{MPa}$ for abnormal transients. For accidents, the criteria considered in the preceding study are: PCST $<1260 \mathrm{C}$, peak pressure $<30.3 \mathrm{MPa}$, and the peak fuel enthalpy $<230 \mathrm{cal} / \mathrm{g}$ [15]. In this study, the fuel enthalpy is not explicitly evaluated due to limited modeling in the current study. It is to be considered in the future study.

The main scenarios considered in this study are uncontrolled CR withdrawal for abnormal transient and CR ejection for Reactivity Initiated Accident (RIA). The reference speeds of the CR withdrawal is tentatively assumed as $114 \mathrm{~cm} / \mathrm{min}$, respectively by referring to that of the preceding study [5]. The CR ejection is assumed to have finished in $0.1 \mathrm{~s}$, which refer to the same scenario of PWR. The reactivity curves for the two reference scenarios are tentatively determined by referring to the scram curve of the Super LWR [1].

\section{SAFETY ANALYSIS RESULTS}

\subsection{Uncontrolled withdrawal of control rod}

The plant behavior during abnormal withdrawal of the $\mathrm{CR}$ at full power is shown in Fig. 3. The core power increases until it reaches the scram set point (120\% of the rated power). The feedwater flow rate is increased by the feedwater pump to keep the main steam temperature constant at around $470 \mathrm{C}$ until the reactor scram. The reactor pressure is kept at the operating pressure of $25 \mathrm{MPa}$ during the transient. The peak cladding surface temperature (PCST) of about $708 \mathrm{C}$ is recorded in the upper MOX fuel layer just after the reactor scram.

Then, sensitivity analyses are conducted with different Doppler reactivity coefficients as shown in Fig. 4 . The larger negative value of the Doppler reactivity coefficient lead to slower core power increase and slightly higher PCST. Other sensitivity analyses are conducted with different CR withdrawal speed, inserted reactivity, without coolant density reactivity feedback, and without feedwater flow rate control system. The speed of CR withdrawal has a larger sensitivity compared to other factors, because the slower CR withdrawal delays the scram actuation and it causes a high PCST in the upper MOX region. 
Summary of the sensitivity analysis results is shown in Table II. Overall, the plant response to uncontrolled withdrawal of $\mathrm{CR}$ is found to be mild and not sensitive to the parameters summarized in Table II.

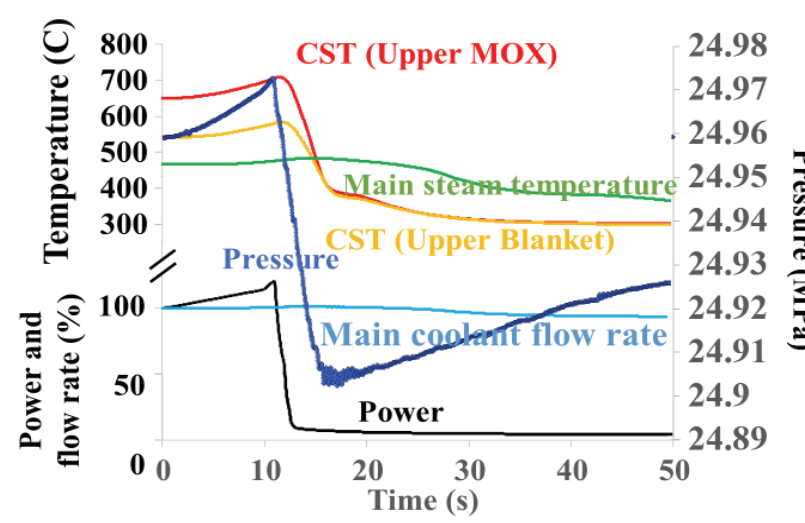

Figure 3: Plant behavior during uncontrolled withdrawal of CR

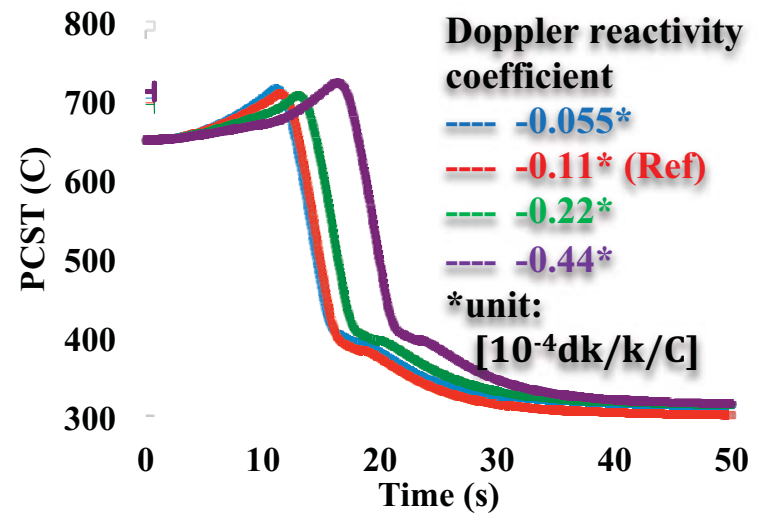

Figure 4: Sensitivity of the Doppler reactivity coefficients on PCST

Table II: Summary of sensitivity analyses for uncontrolled CR withdrawal at full power

\begin{tabular}{|c|c|c|c|c|c|}
\hline & $(1)$ Ref & $(2)$ & $(3)$ & $(4)$ & $(5)$ \\
\hline $\begin{array}{c}\text { Doppler reactivity coefficient } \\
{\left[10^{-4} \mathrm{dk} / \mathrm{k} / \mathrm{C}\right]}\end{array}$ & -0.11 & $\underline{\mathbf{- 0 . 0 5 5}}$ & -0.11 & -0.11 & -0.11 \\
\hline $\begin{array}{c}\text { CR withdrawal speed } \\
\text { (cm/min) }\end{array}$ & 114 & 114 & $\underline{\mathbf{5 7}}$ & 114 & 114 \\
\hline $\begin{array}{c}\text { Density reactivity coefficient } \\
[\% \mathrm{dk} / \mathrm{k} / \mathrm{g} / \mathrm{cc})]\end{array}$ & 6.20 & 6.20 & 6.20 & $\underline{\mathbf{0 . 0}}$ & 6.20 \\
\hline Feed-water flow rate control & Considered & Considered & Considered & Considered & $\begin{array}{c}\text { Not } \\
\text { considered }\end{array}$ \\
\hline Inserted reactivity (\$) & 0.13 & 0.11 & 0.13 & 0.08 & 0.13 \\
\hline PCST (C) & 708 & 714 & 728 & 715 & 712 \\
\hline
\end{tabular}

\subsection{Control rod ejection}

The plant behavior during CR ejection at full power is shown in Fig. 5. The core power increases rapidly and the scram signal is assumed at $\mathrm{t}=0$ due to "reactor period short $(10 \mathrm{~s})$ " with delay of $0.55 \mathrm{~s}$ before the scram actuation. The reactor power reaches the peak and decreases by the Doppler and coolant density reactivity feedback before the scram. The axial temperature gradient of cladding between the upper MOX and upper blanket greatly increases in a short time. The peak cladding surface temperature (PCST) of about $1142 \mathrm{C}$ is recorded in the upper MOX fuel layer just after the reactor scram.

Then, sensitivity analyses are conducted with different Doppler reactivity coefficients as shown in Fig. 6 and with different delay time of the scram actuation as shown in Fig. 7. The smaller negative value of the Doppler reactivity coefficient lead to larger core power increase and higher PCST. The longer delay of the scram actuation also leads to higher peak power and PCST. Other sensitivity analyses are conducted with different inserted reactivity, CR ejection speed and without coolant density reactivity feedback. Summary of the sensitivity analysis results is shown in Table III. Overall, the plant response to CR ejection at full power is found to be sensitive to the Doppler reactivity coefficient and the reactor scram delay. 


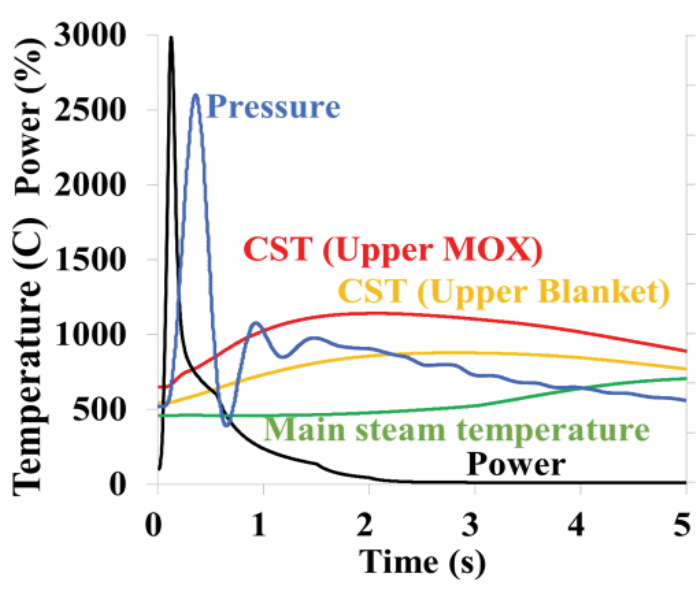

Figure 5: Plant behavior during CR ejection

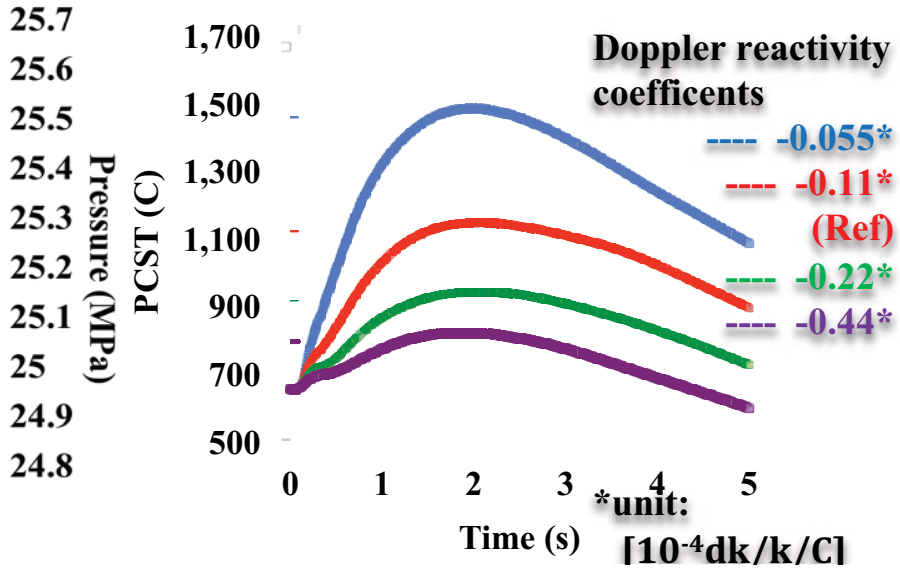

Figure 6: Sensitivity of the Doppler reactivity coefficients on PCST

Table III: Summary of sensitivity analyses for CR ejection at full power

\begin{tabular}{|c|c|c|c|c|c|c|}
\hline & $(1)$ Ref & $(2)$ & $(3)$ & $(4)$ & $(5)$ & $(6)$ \\
\hline $\begin{array}{c}\text { Doppler reactivity coefficient } \\
{\left[10^{-4} \mathrm{dk} / \mathrm{k} / \mathrm{C}\right]}\end{array}$ & -0.11 & $\underline{\mathbf{- 0 . 0 5 5}}$ & -0.11 & -0.11 & -0.11 & -0.11 \\
\hline Delay time of the scram actuation (s) & 0.55 & 0.55 & $\underline{\mathbf{1 . 0}}$ & 0.55 & 0.55 & 0.55 \\
\hline Inserted reactivity (\$) & 1.1 & 1.1 & 1.1 & $\underline{\mathbf{1 . 0}}$ & 1.1 & 1.1 \\
\hline CR ejection speed (m/s) & 14.0 & 14.0 & 14.0 & 14.0 & $\underline{\mathbf{2 8 . 0}}$ & 14.0 \\
\hline $\begin{array}{c}\text { Density reactivity coefficient } \\
{[\% \text { dk / k / g/cc) }]}\end{array}$ & 6.20 & 6.20 & 6.20 & 6.20 & 6.20 & $\underline{\mathbf{0 . 0}}$ \\
\hline Peak power (\%) & 2986 & 5083 & 2986 & 1495 & 3190 & 3240 \\
\hline PCST (C) & 1142 & 1479 & 1237 & 1074 & 1149 & 1144 \\
\hline
\end{tabular}

Fig. 8 shows the axial cladding surface temperature distribution of the hot-channel when the peak value is reached for the three cases: normal operation; uncontrol CR withdrawal; CR ejection. It shows that axial temperature gradients of the cladding are increased especially between the upper MOX and upper blanket by a reactivity inserting. Suppressing such large temperature gradient may be a design issue for the axially heterogeneous core from the viewpoint of ensuring fuel integrity.

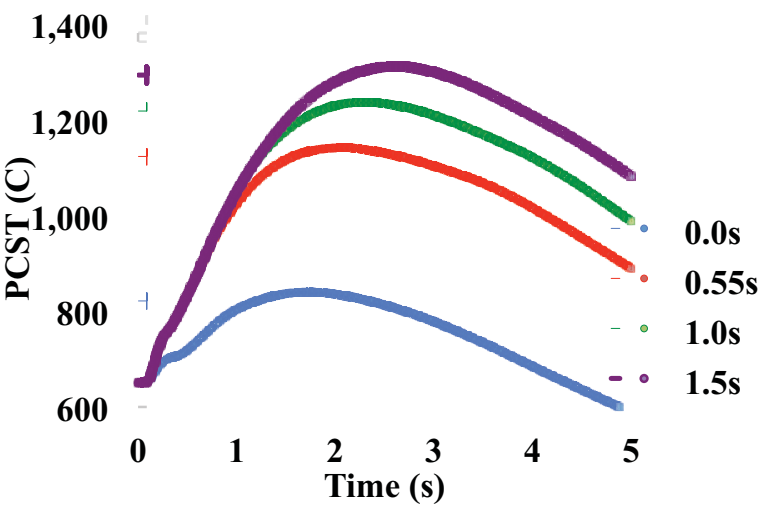

Figure 7: Sensitivity of the delay time of the scram actuation

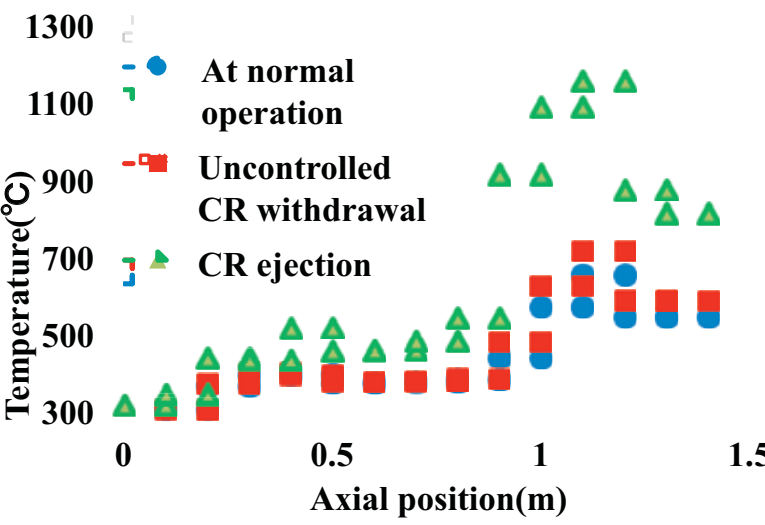

Figure 8: Temperatures of each meshes in hot-channel 


\section{CONCLUSION}

By the power transient analysis of the Super FR with axially heterogeneous core, it is shown that PCST is high at upper MOX region where the temperature of coolant and axial power peaking are high, and the coolability of this region is more severe than that of other regions. It is also shown that axial temperature gradient of cladding greatly increases in a short period. Such a temperature gradient may be verified by a full 3D coupled calculation, although it would have to be addressed in the future study. As two types of fuels are used, the Doppler impact of each type of fuel may also need to be considered in the future study.

\section{ACKNOWLEDGEMENTS}

Part of this work was conducted under "Understanding Mechanisms of Severe Accidents and Improving Safety of Nuclear Reactors by Computer Science" of Institute for Advanced Theoretical and Experimental Physics and Waseda Research Institute for Science and Engineering.

\section{REFERENCES}

1. Oka, Y., Koshizuka, S., Ishiwatari, Y., Yamaji, A., Super Light Water Reactors and Super Fast Reactors, Springer New York Dordrecht Heidelberg London (2010).

2. Oka, Yoshiaki, Mori, Hideo (Eds.), Supercritical-Pressure Light Water Cooled Reactors, DOI 10.1007/978-4-431-55025-9, Springer Tokyo Heidelberg New York Dordrecht London (2014).

3. Q. Liu and Y. Oka, "Single pass core design for a Super Fast Reactor", Annals of Nuclear Energy, 80, pp. 451-459 (2015).

4. International Atomic Energy Agency, Heat Transfer Behavior and Thermohydraulics Code Testing for Supercritical Water Cooled Reactors, Marketing and Sales Unit, Publishing Section International Atomic Energy Agency Vienna International Centre, Vienna, Austria (2014).

5. Sutanto and Y. Oka, Accidents and transients analyses of a super fast reactor with single flow pass core, Nuclear Engineering and Design, 273, pp. 165-174 (2014).

6. Noda, S., Someya, T., Yamaji, A., Flexible core design of Super FBR with multi-axial fuel shuffling, Nuclear Engineering and Design, 324, pp. 45-53 (2017).

7. Sukarman, Noda, S., Fukuda, T., Yamaji, A., Improving breeding performance of Super FR with fuel shuffling in multi-axial layers, Nuclear Engineering and Design, 355, pp. 1-10 (2019).

8. Iwamura, T., Uchikawa, S., Okubo, T., Kugo, T., Akie, H., Nakano, Y., Nakatsuka, T., Concept of innovative water reactor for flexible fuel cycle (FLWR), Nuclear Engineering and Design, 236, pp. 1599-1605 (2006).

9. Liu, X.J., Fu S.W., Xu Z.H. et al, LOCA analysis of SCWR-M with passive safety system, Nuclear Engineering and Design, 259, pp. 187-197 (2013).

10. Noda, S., Sukarman, Yamaji, A. et al, Core design study of Super FBR with multi-axial fuel shuffling and different coolant density, Proceedings of $201826^{\text {th }}$ International Conference on Nuclear Engineering ICONE26, Novotel London West, London, England, July 22-26, 2018 pp. 1-8 (2018).

11. Ikejiri, S., Ishiwatari, Y., Oka, Y., Safety analysis of a supercritical-pressure water-cooled fast reactor under supercritical pressure, Nuclear Engineering and Design, 240, pp. 1218-1228 (2010).

12. C.M. Allison and J.K. Hohorst, Role of RELAP/SCDAPSIM in Nuclear Safety, Science and Technology of Nuclear Installations, 2010, pp. 1-17 (2010).

13. Ishiwatari, Y., Oka, Y., Koshizuka, S., Control of a High Temperature Supercritical Pressure Light Water Cooled and Moderated Reactor with Water Rods, Nuclear Science and Technology, 40(5), pp. 298-306 (2003).

14. Cs. Maraczy, A. Kereszturi, I. Trosztel., Safety analysis of reactivity initiated accidents in a HPLWR reactor by the coupled ATHLET-KIKO3D code, Progress in Nuclear Energy, 52, pp. 190-196 (2010).

15. Oka, Y. et al, Research and development of super light water reactors and super fast reactors in japan, Proceedings of the ISSCWR-5, Vancouver, British Columbia, Canada, March 13-16 (2011). 